\title{
Effect of Cognitive Behavioural Therapy on Pupils with Attention Deficit Hyperactivity Disorder in Two Selected Primary Schools in Cape Coast Metropolis, Ghana
}

\author{
Dr. Felix Senyametor \\ Department of Education and Psychology \\ University of Cape Coast, Ghana \\ Dr. Vera Arhin \\ Rebecca Kaedabi-Donkor \\ Dr. Lydia Aframea Dankyi \\ Kwame Nkrumah \\ College of Distance Education \\ University of Cape Coast, Ghana
}

Doi:10.19044/esj.2021.v17n35p146

Submitted: 17 July 2021

Accepted: 15 September 2021

Published: 31 October 2021

\author{
Copyright 2021 Author(s) \\ Under Creative Commons BY-NC-ND \\ 4.0 OPEN ACCESS
}

Cite As:

Senyametor F., Arhin V., Kaedabi-Donkor R., Dankyi L.A. \& Nkrumah K. (2021). Effect of Cognitive Behavioural Therapy on Pupils with Attention Deficit Hyperactivity Disorder in Two Selected Primary Schools in Cape Coast Metropolis, Ghana. European Scientific Journal, ESJ, 17 (35), 146. https://doi.org/10.19044/esj.2021.v17n35p146

\begin{abstract}
This study focused on investigating the effect of the Cognitive Behavioural Therapeutic treatment (CBT) on pupils with Attention Deficit Hyperactivity Disorder (ADHD) at Bekkyford and Felicomfort Primary Schools in Cape Coast, Ghana. The quasi-experimental design was used for the study. The sample for the study was 43 participants which include 8 parents, 6 teachers, 16 siblings of participants, 13 pupils made up of 9 males and 4 females. The pupils were purposively sampled for the study with the aid of the Scheduled for Affective Disorders and Schizophrenia for School-Aged Children (K-SADS). Data were collected with the Scheduled for Affective Disorders and Schizophrenia for School-Aged Children (K-SADS), questionnaire, and Clinical Global Impression Severity Scale (GCI-I). The results revealed that three out of the 9 males (representing 30 percent) reported minimal improvement in their symptoms regarding impulsivity and inattentiveness. There was a significant difference between the experimental
\end{abstract}


group $(\mathrm{M}=18.70, \mathrm{SD}=2.243)$ and the control group $(\mathrm{M}=08.45, \mathrm{SD}=4.185)$, $\mathrm{t}(37)=8.023$; sig. $=.003, \mathrm{P}<.05$ with respect to the CBT. It was recommended that parents, teachers and siblings should be included in all psychosocial interventions for people with ADHD for lasting and effective management of the symptoms.

Keywords: Attention deficit, hyperactivity cognitive, behavioural therapy, disorder

\section{Introduction}

Attention Deficit Hyperactivity Disorder (ADHD) is one of the commonest neurobehavioural disorders among children of school-going age as well as adults. The National Centre for Birth Defects and Developmental Disabilities (NCBDDD) (2021) refers to Attention Deficit Hyperactivity Disorders as a neurodevelopmental disorder in children and adolescents which results in inattentiveness, impulsivity, or being overly active. Hansa and Bhargava (2021) also defined ADHD as a brain disorder that adversely affects how people pay attention, remain calm and control their behaviours. This could be precipitated by factors, brain injury, and exposure to environmental hazards like alcohol and tobacco use in the first trimester of pregnancy.

Hansa and Bhargava (2021) further added that ADHD is the most frequently diagnosed brain disorder in pupils with males most likely to suffer from it than females. It is usually observed in the formative years when a child begins to exhibit challenges paying attention. This disorder exists in three forms subject to which type of conditions are most conspicuous in the individual. The forms according to the NCBDDD (2021) are: First, Predominantly inattentive presentation, which occurs when it becomes very difficult for the patients to organise themselves to complete a task, pay rapt attention to details and follow the lines of dialogue or instructions. Individuals easily forget instructions and are unable to pay attention to details of everyday routines. Second, Predominantly Hyperactive-Impulsive Presentation: Persons suffering from this condition often play around and are flippant. It is also challenging for such individuals to remain calm for an extended period during dinner, doing home assignments and class exercises among others. Young children often run, jump up and down incessantly. Adults and children who are impulsive may rudely interrupt others during conversation, have difficulty listening, waiting, and taking their turns in activities. An impulsive person usually suffers multiple accidents and injuries than other people. The third one is a Combined Presentation, which registers the combination of the previous two (Predominantly inattentive and Predominantly HyperactiveImpulsive presentations) conditions which is a very severe form of ADHD. The NCBDDD (2021) posited that it is normal for children to experience 
challenges concentrating and behaving well sometimes. However, children with ADHD just fail to outgrow these behaviours.

Research has shown that pupils suffering from ADHD conditions struggle to pay sustained attention to issues requiring deep concentration, appear not to listen when spoken to, fail to comply with directives, and usually do not finish academic tasks. Others face challenges putting their tasks and activities in order and going through mentally demanding activities, easily strayed by inconsequential environmental stimuli, and are forgetful (Flores \& Parra, 2014; APA, 2013). Pupils suffering from ADHD shout out responses before questions are completed, suddenly interrupt or interfere with others' conversations to the extent of triggering problems in social, academic, and job places (APA, 2013; Shillingford, Lambie \& Walter, 2007).

The impulsive persons rush through assigned tasks thereby omitting accurate responses. This is the condition referred to as the impulsive cognitive style, which is the penchant to solve cognitive tasks quickly and inaccurately (Lopez, Serrano, Delgado, Llano, Albe-rola, Sacristán, Pérez \& Camina (as cited in Flores \& Parra, 2014). Impulsive pupils often act on incomplete information and instructions to solve or answer questions without thinking thoroughly, because they omit key steps for an accurate problem-solving approach which require observation, gathering of relevant information, analysing, rejecting redundant data, devising an action plan, scrutinizing every possible answer, foreseeing the possible consequences of each answer, making a decision, checking the answer, congratulating oneself if the answer is accurate or probing the information and all alternatives again to see whether if the answers are correct or wrong (Orjales, 2002).

Studies conducted have shown that the multiplicity of family-related factors including high birth order, large family sizes, and single parenting were associated with ADHD conditions (Hurtig et al., 2007). Abolfotouh (as cited in Al Hamed et al., 2008) confirmed in his study conducted in Saudi Arabia that families more than four were two and half times likely to suffer behavioural disorders compared to smaller families. They further revealed that high birth order of five or more was three times more likely to experience behavioural disorders than families with low birth order. Maternal-related issues such as low birth weight and artificial infant feeding practices have also been reported by some studies to be considerably linked with ADHD (Sasaluxnanon \& Kaewpornsawan, 2005). Children with ADHD are at a bigger risk of a broad range of adverse consequences, such as depression, academic failures, dropout, learning disabilities, and conduct disorders (Children and Adults with Attention-Deficit/Hyperactivity Disorder (CHADD), 2003). 


\section{The effect of CBT on ADHD}

CBT is a psychosocial intervention that aims at improving psychological wellbeing. CBT focuses on challenging and changing unhelpful mental distortions and behaviours, improving thereby emotional regulation and the development of self-coping techniques that target solving current problems (Beck, 2011). Research has, however, shown that patients who received CBT showed a significant reduction of ADHD symptoms as compared with the control group on the Clinical Global Impression SelfReport Scale $(\mathrm{p}<0.001)$ and the Clinical Global Impression Clinician-Report Scale $(\mathrm{p}<0.001)$ (Pettersson \& Atten, 2017). Peterson further revealed that participants who received CBT had a significant lessening in functional impairment with the controlled group on the Global Assessment of Functioning $(\mathrm{p}<0.001)$ and the Weiss Functional Impairment Rating Scale Parent Version $(\mathrm{p}<0.05)$. In a related study, Doyle and Terjjesen (2005) also established that patients who received CBT reported increasing treatment compliance, managing many of the emotive and social difficulties that accompanied the disorder, preventing further difficulties, and assist the student and family in reducing difficulties and enhancing the quality of their lives and their relationships.

Orjales (2002) found that CBT was able to help children to regulate their own behaviours in line with rules, control their daily activities, use techniques to conduct themselves properly, select relevant data from irrelevant information, self-gauge their judgments, and develop healthy self-esteem and cordial relationships with others. For example, children with ADHD register stop-signal reaction time owing to cognitive impairments rather than behavioural inhibition deficit (Alderson, Rapport \& Kofler, 2008). This means that those children are so uninhibited that they cannot stop and take a moment to think about something ahead of time.

DuPaul, Reid, Anastopoulos, Lambert, Watkins, and Power (2016), with the aid of the ADHD Rating Scale-5(DSM-5) developed by the American Psychiatric Association (2013) examined the fit of a correlate, two-factor structure of ADHD to determine whether ADHD symptom ratings varied across child and demographic characteristic. The samples used include: (1) 2,079 parents and guardians ( $\mathrm{N}=2,079 ; 1,037$ males, 1,042 females) completed ADHD symptom ratings for their wards between 5 and 17 years old $(\mathrm{M}=10.68 ; \mathrm{SD}=3.75)$ and (2) 1,070 teachers (766 female, 304 male) completed ADHD condition ratings for pupils $(\mathrm{N}=2,140 ; 1,070$ males, 1,070 females) between 5 and 17 year olds $(M=11.53$; $\mathrm{SD}=3.54)$ who went through preschool to 12th grade. The results showed that males were higher in symptom frequency than their female counterparts; older pupils were rated less than younger children, especially for hyperactive-impulsive conditions. 
The findings revealed that CBT produced a higher positive impact in reducing ADHD symptoms in girls than boys (DuPaul et al, 2016)

Some studies have revealed that prominent symptoms and impairments related to the disorder persist into adulthood in approximately one-half of cases (Faraone \& Mick, 2000, Mick, Faraone, Biederman \& Spencer, 2004). There appears to be developmental variance in the ADHD symptom profile across the life span. Longitudinally derived data in ADHD youth growing up indicate that the symptom cluster of hyperactivity and impulsivity decays over time, while the symptoms of inattention largely persist (Millstein, Wilens, Biederman \& Spencer, as cited in Timothy, Wilens, \& Thomas, Spencer, 2013).

A meta-analysis on the difference between patients of ADHD who went through treatment with only CBT, those who did not go through CBT at all but had placebo and those who had only pharmacological treatment revealed that, even though pharmacological treatment proved very useful in treating ADHD, the patients did not attain complete remission as compared to patients who went through treatment with only CBT along with coping strategies. Those who did not go through CBT at all had no improvement in their symptoms (Faraone, Spencer, Aleardi, Pagano, Biederman, 2004; Mick, Faraone, Biederman, 2004). A follow-up study a few years later by Weiss, Murray, Wasdell, Greenfield, Giles \& Hechtman (2012) confirmed that both the experimental group and control group between the ages 18 to 66 experienced great improvement in their conditions and functioning, however, pharmacological treatment (medication) did not significantly improve outcome over and above use of CBT.

Research has further shown that non-pharmacological (educational remediation, individuals and family psychotherapy) interventions are superior to pharmacological interventions in the management of ADHD (Steven \& Safren, 2021). Steven and Safren (2021) revealed that psychopharmacological intervention proved effective in reducing the ADHD symptoms such as attention deficits, high activity, and impulsive conditions by 50 percent with some few cases of relapse, while non-pharmacological intervention like CBT proved very effective in reducing symptoms associated with functional impairments by 70 percent with no relapses because it equips the participants with coping and problem-solving strategies that last lifetime. Patients with no interventions however experienced aggravated symptoms of ADHD.

\subsection{Problem Statement}

Attention Deficit Hyperactivity Disorder (ADHD) is quite common in most schools, especially basic and second-cycle institutions but sadly, most teachers and managers of these institutions lack the expertise to detect, treat or refer for treatment (Doyle \& Terjjesen, 2005). Students with ADHD are 
often not understood by most teachers. This often generates a lot of disciplinary issues in the schools. Some schools in the Cape Coast Metropolis are no exception. As part of our occasional rendering of psychological services in the Cape Coast Metropolis, we had the opportunity to visit Bekkyford and Felicomfort Primary schools to identify pupils with psychological needs and how to put interventions in place to treat them to enhance their academic outcomes. Nine students (6 from Bekkyford and 3 from Felicomfort schools) were initially identified as truants.

Through interaction, their teachers and the management of the school vehemently complained to us about their truancy, inattentiveness, lack of patience, and poor academic performances. We, therefore, assessed the pupils using the Scheduled for Affective Disorders and Schizophrenia for SchoolAged Children (K-SADS-PL).

A few studies conducted on the effect of CBT on ADHD in America, Canada, and British Columbia were on adults between the ages of 18 and 70, which revealed significant positive effects of the CBT on the participants with ADHD (Kaufman et al, 1997; Doyle \& Terjjesen, 2005; Weiss, Murray, Wasdell, Greenfield, Giles \& Hechtman, 2012; Steven \& Safren, 2021; Dupaul et al, 2016; Pettersson \& Atten, 2017; NCBDDD, 2021). In the light of the foregoing findings, one wonders whether Cognitive Behavioural Therapy (CBT) would have the same positive impact on participants who were pupils between 9 and 11 years in the current study. It appears there has not been any scientific research in the existing literature on the phenomenon at Cape Coast in the Central Region of Ghana. This is the research gap in the existing literature that this study has come to fill.

\subsection{Purpose of the Study}

The objective of this study was to examine the effect of Cognitive Behavioural Therapy on students with Attention Deficit Hyperactivity Disorder. The study objectives are to investigate the:

Effect of Cognitive Behavioural Therapy on pupils with Attention Deficit Hyperactivity Disorder with respect to impulsivity and inattentiveness at primary schools in the Cape Coast metropolis.

Effect of Cognitive Behavioural Therapy on pupils with Attention Deficit Hyperactivity Disorder with respect to distractibility and avoidance of tasks at primary schools in the Cape Coast metropolis.

The difference in symptoms between participants who went through the CBT (the experimental group) and participants who did not (the control group). 


\subsection{Research Question}

What is the effect of Cognitive Behavioural Therapy on pupils suffering from Attention Deficit Hyperactivity Disorder with respect to impulsivity and inattentiveness at primary schools in the Cape Coast metropolis?

What is the effect of Cognitive Behavioural Therapy on pupils suffering Attention Deficit Hyperactivity Disorder with respect to distractibility and avoidance of tasks at primary schools in the Cape Coast metropolis?

\subsection{Hypothesis}

${ }^{1} \mathrm{H}_{0}$ : There is no statistically significant difference in symptoms between a participant who went through the CBT (the experimental group) and participants who did not.

\subsection{Methodology}

\subsection{Research Design}

This study employed the Quasi-experimental design to examine how two non-equivalent groups fared concerning the CBT. The strength of this design is that it enabled us to compare scores of the participant before and after the intervention in the treatment group with the control group. The limitation of this design, however, is the lack of randomization. This restricted the study's ability to establish a conclusive causal relationship based on the study.

\subsection{Population}

The target populations were all students and their siblings from Bekkyford and Felicomfort primary schools totaling 506 made up of 191 males, 114 females, and 201 siblings (97 males and 104 females) in the Cape Coast metropolis. The accessible population was 238 made up of 91 siblings, 11 teachers, 75 pupils (comprising 34 males, 41 females), and their parents (68) from both schools.

Parents and siblings were part of the study because psychosocial interventions for ADHD patients are possible and effective, if they are involved in the treatment process to understand the process, better understand the condition of their relative (the patient) and cooperate with the researchers or physicians and the patient to ensure successful assessment and treatment of symptoms (Weiss, Murray, Wasdell, Greenfield, Giles \& Hechtman 2012; Steven \& Safren, 2021). 


\section{3. $\quad$ Sampling Technique}

A sample of 43 participants was selected for the study. It includes 8 parents, 6 teachers, 16 siblings of participants, 13 pupils made up of 9 males and 4 females with the aid of the Scheduled for Affective Disorders and Schizophrenia for School-Aged Children (K-SADS) developed by Kaufman, Birmaher, Brent, Rao, Flynn, Moreci, Williamson, and Ryan (1997) the participants were purposively sampled for the study. The students were identified through the K-SADS-PL assessment interview. The parents and teachers of the participants were also identified and purposively sampled for the study.

\subsection{Instruments for Data Collection}

Three data collection instruments were used in this study; a closedended questionnaire, Scheduled for Affective Disorders and Schizophrenia for School-Aged Children (K-SADS), and Clinical Global Impression Severity Scale (GCI-S). The questionnaire (adapted from the GCI-I and K-SADS) was used to solicit responses on how participants felt after the CBT. The K-SADS was used as a diagnostic tool to identify and select participants with ADHD for the study. The GCI-S was used to assess participants after the CBT intervention to measure their level of improvement. The Scheduled for Affective Disorders and Schizophrenia for School-Aged Children (K-SADS) developed by Kaufman, Birmaher, Brent, Rao, Flynn, Moreci, Williamson, and Ryan (1997) was developed in line with the Diagnostic and Statistical Manual of Mental Disorders, $3^{\text {rd }}$ and $4^{\text {th }}$ editions (DMS-III-R/DMS-IV). The K-SADS according to Kaufman, Birmaher, Brent, Rao, Flynn, Moreci, Williamson, and Ryan (1997) is a "semi-structured diagnostic interview designed to assess current and past episodes of psychopathology in children and adolescents ages 6-18 according to DSM-III-R and DSM-IV criteria". This instrument was adopted. It has three sections (A, B, and C). Section A focuses on substances (alcohol, wee, cigarette, and any other substance in general), Section B, addresses current and past substance abuse. The last section covers affective disorders, psychotic disorders anxiety disorders, and behavioural disorders (section C). Only sections B and C were adopted and used in this study. The strength of this instrument lies in diagnosing psychotic, affective, and anxiety disorders which is the crux of ADHD (Kaufman et al, 1997).

The GCI-S is a 7 seven-point rating scale that requires researchers to rate the severity of the participants diagnosed with ADHD at the time of assessment relative to past experience with them (Alane, Emmanuelle \& Bruno 2007). This instrument has three (GCI-S, GCI-I, and GCI-E) levels for measuring the severity of the present condition, improvement in the condition 
after the intervention, and assessing the efficacy index of the therapeutic effect of treatment respectively.

\subsection{Data collection Procedure}

The K-SADS was administered through interviews of participants and their parents and finally achieving the summary of the ratings. A single diagnostic module of K-SADS was used for multiple interviews of the participants during treatment to assess the change of symptoms. The process spanned six months. The GCI-S instrument was used to establish the baseline symptoms for participants with ADHD (this served as a pre-test). The assessment of participants after the CBT intervention was done using the GCII (this also served as the post-test).

\section{Ethical Issues}

The study employed the following ethical issues about the involvement of respondents in the study and collection of data: Informed consent, anonymity, confidentiality, privacy, and debriefing. To assist participants to make an informed choice regarding whether or not to participate in the study voluntarily or not, issues about possible risks, intrusion of privacy, the risk to dignity, physical harm, and how they would be compensated as well as benefits of the research were communicated to them. This was done through the issuance of consent forms to the participants, parents, and siblings to fill. Freedom to withdraw from the study at any given time in the process of the study too was thoroughly explained to them.

As part of masking the identities of respondents, Pseudonyms such as Bekkyford School (Treatment Group) and Felicomfort School (Control Group) were used in the study. Furthermore, participants were not required to provide their names on the questionnaire administered. They were assured that any private information about their beliefs, opinions, and records disclosed would not be shared with any other party without their authorization or knowledge. In line with the principle of debriefing, the objectives of the study, instruments, and methodology aspects of the study were thoroughly discussed with the participants.

\section{Explication and Analysis of Data}

Qualitative data were edited and delineated into themes such as impulsivity, inattentiveness, avoidance, and distractibility. The data were explicated using the GCI-I assessment tool to establish how participants' symptoms have improved. Hypothesis one was tested using the independent sample t-test. 


\section{6. $\quad$ Pretest}

In line with Alane, Emmanuelle and Bruno (2007) we used this adapted instrument (GCI-S) to measure the present level of severity of the participants' ADHD which served as a baseline score for the pretest. In harmony with Guy and William (as cited in Wikipedia, 2020) the following ratings were administered at level one for participants to tell how they feel about their conditions

Normal, not at all ill (able to sit still and listen to teacher till lessons end, complete assignments, take time to answer questions correctly, get good grades for exams and exercises)

Borderline mentally ill (able to sit still and listen to teacher till lessons end, complete assignments, take time to answer questions correctly, get good scores for exams and exercises)

Mildly ill (once a while able to sit still and listen to teacher till lessons end, complete assignments, take time to answer questions correctly, get good scores for exams and exercises)

Moderately ill (a few times notable to sit still and listen to teacher till lessons end, complete assignments, take time to answer questions correctly, get good scores for exams and exercises)

Markedly ill (sometimes not able to sit still and listen to teacher till lessons end, complete assignments, take time to answer questions correctly, get good scores for exams and exercises)

Severely ill (anxious, angry, and depressive, not able to sit still and listen to teacher till lessons end, complete assignments, take time to answer questions correctly, get good scores for exams and exercises) Among the most extremely ill participants (anxious, angry, and depressive, all the time not able to sit still and listen to teacher till lessons end, complete assignments, do assignments, take time to answer questions correctly, get good scores for exams and exercises)

\subsection{Pre-test Results}

After the GCI-S was administered all 13 participants were identified and categorized as those having problems with impulsivity and inattentiveness, 9 out of the 13 had problems with distractibility avoidance and of responsibility, anxiety, and depressive symptoms (Found on scale number 6 and 7). Based on this result, interventions were planned for the participants. Two unrandomised intact groups were used. Nine pupils made up of 6 males and 3 females at Bekkyford Primary school formed the experimental group, and 4 participants made up of 3 males and 1 female formed the control group at Felicomfort Primary School. 


\subsection{Intervention}

Since the behaviour of the people who exhibit ADHD characteristics has to do with thinking and feelings, Cognitive Behavioural Therapy (CBT) was adopted in modifying the participant's behaviour. CBT is the most cutting-edge, research-supported treatment for numerous psychological behaviour problems and disorders.

In CBT, ADHD children are taught to use self-instruction, selfmonitoring, self-reinforcement, and motivational strategies to develop selfcontrol of their attention and impulse behavioural problems (Purdie, Hattie \& Carrol, 2002). By so doing, any associated distress can be reduced by teaching new information-processing skills and coping mechanisms (Beck, 2011). It is against this background that we chose to embark on a 6-month intervention using the CBT. The CBT was focused on behavioural change in line with Miechenbaum and Goodman (as cited in Orjales, 2007). These include:

\subsection{Self-instructional Training to treat Impulsivity and Inattentiveness}

Self-instructional training is a cognitive technique that was used to teach participants the procedure of beneficial thoughts for solving problems to replace negative thoughts created (Orjales, 2007). The self-instructional training for the experimental group in this study was based on the model developed by Miechenbaum and Goodman (as cited in Orjales, 2007) which challenges the impulsive and inattentive participants to restructure their cognitive processes in problem-solving the right way and patiently. Parents of the control group were counseled to seek pharmacological treatment for their wards.

The procedure is as follows: 1) Firstly, I watch and say what I see, 2) what do I have to do? 3) How would I do it?, 4) I have to pay attention carefully (and look at all possible answers), 5) I can do it!, 6) Great! I did a good job/ I did not get the correct answers. Why? (I review all the steps) Ahhh!. This is the reason why! Next time I wouldn't make any mistakes (Orjales, 2007). The participants were taken through these techniques of spoken mediation and selftalk. This helped participants to pay extended attention and stayed focused on a task. At the same time, the cognitive self-instructional training of Miechenbaum and Goodman assists children with processing cognitive thoughts into adaptive acceptable behaviours. This model is often engaged to assist learners with impulsivity challenges. For instance, ADHD pupils who shout out responses before waiting for their turn during classroom discussion were taught to give the responses silently to themselves, without interrupting the whole class; they were also taught to say words of restraint to themselves, such as "I can patiently wait my turn or "I know the answer, but I'll wait my turn patiently". The procedures of this training are as follows: a) participants 
were trained to become aware of their maladaptive thoughts, b) we modeled the acceptable behaviours while uttering effective actions strategies, c) the participants then performed the targeted behaviours while uttering acceptable self-instruction and executing them out (Shilingford, Lambie \& Walter, 2007). Participants were further trained and taken through the process of daily thinking of only positive and healthy things that they could do for themselves irrespective of what others think of them. They were also encouraged to say well-meaning words to themselves for confidence building. For example, they were taught to say "I can be the best and well-behaved pupil in class only if I try a little harder". This self-talk was used throughout the three months.

\subsection{Avoidance and Distractibility}

Children with ADHD usually have a problem staying on task without being distracted and avoiding tasks. Steven and Safren (2021) procedure was adapted to treat participants as follows:

Assignments in Mathematics, reading passages in the English language and Social studies were given to participants in their homework notebooks with dates. Participants were taught to locate the list of tasks in the notebooks and work on them. This session also included repeated training of participants in problem-solving targeted at helping participants to overcome distractibility and avoidance of tasks. Tasks in their notes books were broken down into easier and manageable units and steps for them. Assignments were inspected each day to check on participants' progress. The last part of this aspect of the CBT was training participants to prioritise assignments and tasks given to them, by categorizing them into A (most urgent but involving), B (urgent but not very involving), $\mathrm{C}$ (not urgent and less involving). We were careful not to use the word 'difficult' as most children with ADHD are easily frustrated and put off by associating tasks with that word. There were trained to see every new task assigned to them as relatively easy by breaking them into smaller and manageable units before working on them. They were also counseled on the importance of education and each task assigned to them. This session was meant to help them respect the urgency of responsibilities or tasks to enable make informed decisions and be able to stay on tasks and not avoid them.

\subsection{Intervention for Teachers and Parents}

Research has shown that most parents and teachers are ignorant of the existence of ADHD and how it impacts the behaviour of children (Pettersson \& Atten, 2017). Steven and Safren (2021) however found that providing psychosocial support for families and teachers in the form of coping strategies is key to easing symptoms in children with ADHD. The following support 
was, therefore, administered to parents, teachers, and siblings of the participants:

Therapy for participants' Families and Teachers: Parents, teachers, and siblings of participants were invited to attend the CBT along with them. This was done to enable them to understand the conditions of the participants better and be able to assist them at home and school to overcome their problems thereby improving their relationships with the participants.

Training for Parents and Teachers: parents and teachers were taught techniques and strategies to increase safety for the participant at home and school if they register aggressive or violent behaviours. The ultimate objective of this training was to assist parents, teachers and siblings interact more effectively with the participants to help improve and regulate their behaviours.

They were, therefore, taken through the following coping strategies.

Enforcing limits concerning rules at home and school

Providing clear instructions

Breaking down tasks into smaller units for participants in increasing levels of difficulty and making sure tasks are not beyond them.

Making sure that positive behaviours of participants regarding sitting still and staying focus on doing chores and assignments are rewarded Using time-out after bad behaviours and outburst

Being consistent and eschewing getting into arguments and verbal exchanges with the participants over consequences or what happened Creating room for the participants to vent their frustrations and if possible provide a pillow to punch or yell into.

\subsection{Post Intervention}

The GCI-I was also used to assess how the participants' ADHD symptoms had improved or worsened relative to the baseline at the onset of the intervention. In line with Guy and Williams (as cited in Alane, Emmanuelle \& Bruno, 2007)) ratings, the following were used as themes for interview of participants to express how they felt and improved after the intervention, which was based on self-reports from participants and parents:

Extremely improved condition

Improved a lot

Improved slightly

There is no change in symptom

Slightly worse

Much worse

Very much worse 


\subsection{Results on Impulsivity and Inattentiveness}

The CGI-I assessment interview was used to assess participants of the experimental group at the end of the CBT after three months. The assessment together with participants' self-report batteries fell on 1-2 on the GCI-I scale. Six out of 9 participants representing 70 percent were able to perform targeted behaviours while uttering acceptable self-instruction and trying them out while 3 (all males) out of 9 representing 30 percent reported minimal improvement ( 3 on the scale). The finding supports that of DuPaul et al., (2016) who found that generally, boys were higher in symptom frequency than girls. This finding further corroborates that of Pettersson and Atten, (2017) who found that participants who underwent CBT recorded a remarkable improvement in their conditions compared with the control group on the Clinical Global Impression Self-Report Scale and the Clinical Global Impression Clinician-Report Scale.

\subsection{A sample of Self-reports from Participants, Teachers, and Parents regarding CBT impact on Impulsivity and Inattentiveness}

A pupil said "I've stopped roaming about in class and able to finish my class exercises"

Four other pupils also indicated that "My three friends and I were awarded by our class teacher for always paying attention and doing our class work and doing better than others"

A teacher reported that "I never knew that the indiscipline I always see in class regarding to those pupils was due to ADHD. Relatively, their symptoms have drastically reduced. I'm applying the coping strategies to help them more"

A Basic 5 teacher also said "the symptoms of my pupils with respect to impulsivity and inattentiveness are not completely gone but are relatively better than before"

A parent said "My child is now relatively better. He now takes time to respond wisely and correctly to questions"

A certain parent also spoke on behalf of two others that "our children are not completely cured but relatively are better able to sit still we are helping them do their home works.

A parent from the control group reported that "As for children only prayers can help them"

\subsection{Results on Avoidance and Distractibility (Research question Two)}

Participants were assessed together with independent assessors (parents and teachers) through the interview based on the GCI-I. Independent assessment and participants' self-reports contained a rating of GCI-I indicated 6 out of 9 representing 80 percent only reported 'much improved' symptoms 
on the GCI-I scale (number 2) while 2 (all males) representing 20 percent (number 4 on the scale) reported 'no change'. The finding is in congruence with that of DuPaul et al, 2016 who found that CBT produced a higher positive impact in reducing ADHD symptoms in girls than boys. This finding is also in line with Steven and Safren (2021) who reported 56 percent improvement for participants who went through CBT as compared to 13 percent who did not undergo CBT. Parents were also participants because, most of them could not identify and help managed pupils with ADHD, thus needed intervention. They were also used as assessors because they lived daily with their wards with ADHD and could easily assess and tell whether or not there was an improvement in the conditions of their wards as a result of the CBT administration.

\subsection{A sample of Self-reports from Participants, Teachers, and Parents regarding CBT impact on Impulsivity and Inattentiveness}

A parent reported that "In fact, I've seen great change in my two children; they are able to do house chores and remaining focused better than before"

Six other parents also reported that "now because we are applying the coping strategies and the training we received to help our children, their running away from tasks and troubles are relatively reduced. The condition is not completely gone but gradually with our help it will go'

Two pupils also said "now, were are able to stay in school, finish copying notes from the board"

Another parent reported however said that "honestly, l did not see any change in my child. I'll apply the coping strategies to see whether there will be a change"

Two parents of the control group said that "our children are still misbehaving. We'll take them to hospital"

The post-intervention interview assessment with the GCI-I and selfreports from participants pointed to the fact that the CBT contributed significantly to the reduction in symptoms of participants with ADHD compared with the control group. There was a question about the extent of the difference in improvement in symptoms of the treatment group and the control group. This was addressed by testing the hypothesis of the study using a t-test.

\subsection{Hypothesis One: There is no statistically significant difference between participants who went through the CBT (the experimental group) and participants who did not.}

After the intervention and findings that emanated from the qualitative results, for triangulation purposes, we went further to find out whether there 
existed any significant difference between the treatment group and the control group regarding the effect of the CBT. The results are presented in Table 1 .

Table 1: Results on the Difference between the Treatment Group and the Control Group concerning CBT

\begin{tabular}{cccc}
\hline MeanSD t & df & $\begin{array}{l}\text { P-value } \\
\text { (sig-value) }\end{array}$ & $\eta^{2}$ \\
\hline CBT $^{\text {Treatment } 18.702 .243}$ & 8.02137 & $.002 *$ & 0.87 \\
Control & 08.454 .185 & & \\
\hline
\end{tabular}

Source: Field data $(2021) * \mathrm{p}<0.05, \mathrm{df}=37(\mathrm{~N}=13)$

The results in Table 1 show a significant difference between the experimental group $(M=18.70, S D=2.243)$ and the control group $(M=08.45$, $\mathrm{SD}=4.185), \mathrm{t}(37)=8.023$; sig. $=.002, \mathrm{P}<.05$ concerning the CBT. The eta square statistics (0.87) indicated a large effect size. This shows that 85 percent of the variances regarding the improvement in the symptoms of participants with ADHD could be explained by the effect of CBT on them. This finding is in line with that of Pettersson and Atten (2017) who found that participants who received CBT showed a considerably reduced symptom of ADHD compared with the control group on the Clinical Global Impression SelfReport Scale and the Clinical Global Impression Clinician-Report Scale. The finding further corroborates that of Steven and Safren (2021) who reported 56 percent improvement for participants who went through CBT as compared to 13 percent who did not undergo CBT. The findings further corroborate that of Faraone, Spencer, Aleardi, Pagano, and Biederman, 2004; Mick, Faraone, and Biederman, 2004 which revealed that, even though pharmacological treatment proved very useful in treating ADHD, the patients who went through it did not attain complete remission as compared to patients who went through treatment with only CBT along with coping strategies. Those who did not go through CBT at all had no improvement in their symptoms.

\subsection{Key Findings}

Based on the study, the following key findings emerged:

Six out of 9 participants representing 70 percent reported very much improvement in their symptoms. They were able to perform targeted behaviours while uttering acceptable self-instruction and trying them out.

Three (all males) out of 9 representing 30 percent reported minimal improvement in their symptoms regarding impulsivity and inattentiveness

Six out of 9 representing 80 percent only reported 'much improved' symptoms on the GCI-I assessment scale (number 2) regarding avoidance and distractibility. 
Two (males) representing 20 percent (number 4 on the GCI-I scale) reported 'no change' regarding anxiety, depressive thoughts, avoidance, and distractibility.

There was a significant difference between the experimental group (M $=18.70, \mathrm{SD}=2.243)$ and the control group $(\mathrm{M}=09.55, \mathrm{SD}=4.196), \mathrm{t}(37)=$ .802 ; sig. $=.003, \mathrm{P}<.05$ concerning the CBT. The eta square of 0.85 shows that 85 percent of the variances in the improvement of symptoms of participants with ADHD could be explained by the effect of CBT.

\section{Conclusion}

Dealing with an individual with ADHD can be very frustrating and overwhelming indeed. This is because such individuals often lose touch with the realities of life. Based on the findings of this study, ADHD individuals generally have shortfalls in executive functions; the ability to reason and strategise ahead, organise, control impulses, and complete tasks. The earlier and more consistently this problem is addressed for children, the greater chance they have for success in life. All stakeholders including psychologists, parents, and teachers can do a lot to help in containing the symptoms as pertained in this study. ADHD is a neurodevelopmental disorder that cannot be completely cured but could be effectively managed through psychosocial interventions and coping strategies associated with it. The psychosocial treatments as administered in this study are only effective if close relatives and parents are involved in the treatment process and cooperate with the patients and the therapists.

\section{Recommendations}

In line with the findings of the study the following recommendations are made:

Ghana Education Service (GES) should employ well-trained educational and school psychologists for the basic schools to be able to identify and help students with psychopathological problems like ADHD.

The Ministry of Education together with the GES should organize inservice training for basic school teachers on the field to equip them with some basic skills to identify and help children with psychological and maladaptive behavioural problems like ADHD.

Parents and guardians whose wards are suffering from ADHD should seek psychosocial treatment as a first-line solution.

Parents and guardians who are on pharmacological treatment should combine it with psychosocial treatment which so far has proven superior to pharmacological interventions. 
Parents, teachers and siblings should be included in all psychosocial interventions for people with ADHD for lasting and effective management of the symptoms.

\section{Limitation of the Study}

This study could not establish whether or not parents of participants who were told to seek pharmacological interventions for their wards did so. We could not follow up on this, because we were not in the position to confirm whether or not pharmacological treatment was followed to the latter as directed by physicians to parents to be administered to their wards. That process, therefore, could not be controlled by the researchers. This study, therefore, could not confirm whether or not the psychosocial intervention employed in this study was superior to pharmacological interventions as reported in other studies. This study was also, conducted in only two schools, thus, has very limited generalisability.

\section{References:}

1. Alane, K., Emmanuelle, C., \& Bruno, F. (2007). The improved Clinical Global Impression Scale development and validation in depression. BMC Psychiatry. 7 (7) 147-244

2. Alderson, R. M., Rapport, M. D. \& Kofler, M. J. (2007). AttentionDeficit/Hyperactivity disorder and behavioural inhibition: A meta-analytic review of the stop-signal paradigm. Journal of Abnormal Child Psychology, 35(5), 745-758.

3. Alderson, R. M., Rapport, M. D., Sarver, D. E. \& Kofler, M. J. (2008). ADHD and behavioural inhibition: A re-examination of the stop-signal task. Journal of Abnormal Child Psychology, 36(7), 989-998.

4. Al Hamed, J.H., Taha, A. Z., Sabra, A. A., \& Bella, H. (2008). Attention Deficit Hyperactivity Disorder (ADHD) among Male Primary School Children in Dammam, Saudi Arabia: Prevalence and Associated Factors. Journal of the Egyptian Public Health Association 83(4), 166-182

5. American Psychiatric Association (APA). (1994). Diagnostic and Statistical Manual of Mental Disorders $\left(4^{\text {th }}\right.$ ed. $)$. American Psychiatric Association.

6. American Psychiatric Association (APA). (2000). Diagnostic and Statistical Manual of Mental

7. Disorders $\left(4^{\text {th }}\right.$ ed). American Psychiatric Publishing

8. American Psychiatric Association (2013). Diagnostic and statistical manual of mental disorders. ( $5^{\text {th }}$ ed.). American Psychiatric Publishing. 
9. Beck, J.S. (2011). Cognitive behaviour therapy: Basics and beyond. $\left(2^{\text {nd }}\right.$ ed.). The Guilford Press.

10. Children and Adults with Attention-Deficit/Hyperactivity Disorder (CHADD). (2003, Feb 8). Medical management of children and adults with AD/HD_Fact Sheet \#3. http://www.chadd.org/fs/fs3.htm.

11. Doyle, K, A \& Terjjesen, M (2005). Rational-Emotive Behavior Therapy and Attention Deficit Hyperactivity Disorder. https://www.researchgate.net/publication/227247377_RationalEmotive_Behavior_Therapy_and_Attention_Deficit_Hyperactivity_ Disorder

12. DuPaul, G. J., Reid, R., Anastopoulos, A. D., Lambert, M. C., Watkins, M. W., \& Power, T. J. (2016). Parent and teacher ratings of attention-deficit/hyperactivity disorder symptoms: Factor structure and normative data. Psychological Assessment. 28(2) 214-225.

13. Faraone SV, Spencer T, Aleardi M, Pagano C, Biederman, J. (2004). Meta-analysis of the efficacy of methylphenidate for treating adult attention-deficit/hyperactivity disorder. 24 (1), 24-29

14. Flores, G. W. R., \& Parra, V. A. B. (2014). Cognitive behavioral treatment in children with attention deficit hyperactivity disorder. file:///C:/Users/Felix/AppData/Local/Temp/23383-

Texto\%20del\%20art\%C3\%ADculo- 89061-1-10-20150706.pdf

15. Kaufman, J., Birmaher, B., Brent, D., Rao, U., Flynn, C., Moreci, P., Williamson, D. \& Ryan, N. (1997). Schedule for Affective Disorders and Schizophrenia for School-Age Children

Present and Lifetime version (K-SADS-PL, Kiddie-SADS-PL). http://lib.adai.washington.edu/dbtw-

wpd/exec/dbtwpub.dll?AC=QBE_QUERY\&QY=find $\% 20 \% 28$ Acces sNo\%20ct\%20213\%29\%20and\%20\%28Status\%20ct\%20public\%29 $\& \mathrm{XC}=/ \mathrm{dbtw}-$

wpd/exec/dbtwpub.dll\&BU=http\%3A//lib.adai.washington.edu/instru mentsearch.htm \& TN $=$ instruments $\& R N=0 \& M R=0 \& E S=1 \& C S=0 \& X$ $\mathrm{P}=\& \mathrm{RF}=\mathrm{Full} \& \mathrm{DF}=\mathrm{Full} \& \mathrm{RL}=1 \& \mathrm{EL}=1 \& \mathrm{DL}=1 \& \mathrm{NP}=3 \& \mathrm{ID}=\& \mathrm{MF}=$ WPEngMsg.ini $\& M Q=\& T I=0 \& D T=\& S T=0 \& I R=14 \& N R=0 \& N B=0$ $\& \mathrm{SV}=0 \& \mathrm{BG}=0 \& \mathrm{FG}=000000 \& \mathrm{QS}=$

16. Mick E, Faraone SV, Biederman J, \& Spencer T. (2004). The course and outcome of ADHD. Primary Psychiatry. 11(7), 42-48.

17. Mick E, Faraone S.V, \& Biederman J.(2004). Age-dependent expression of attention- deficit/hyperactivity disorder symptoms. 27 (2): 215-224.

18. National Center on Birth Defects and Developmental Disabilities (2021). What is ADHD? https://www.cdc.gov/ncbddd/adhd/facts.html 
19. Orjales, I. (2002). Déficit de atención con hiperactividad: Manual para padres y educadores. Madrid: CEPE.

20. Orjales, I. (2007). El tratamiento cognitivo en niños con trastorno por déficit de atención con hiperactividad (TDAH): revisión y nuevas aportaciones. Anuario de Psicología Clínica y de la Salud, 2(3), 1930.

21. Pettersson R. J Atten, D (2017) Treatment of child, adolescent and adult ADHD. https://adhd-institute.com/disease-management/

22. Purdie, N., Hattie, J. \& Carroll, A. (2002). A review of the research on interventions for attention deficit hyperactivity disorder: What works best? Review of Educational Research, 72(1), 61-99.

23. Sasaluxnanon, C., \& Kaewpornsawan, T. (2005). Risk factor of birth weight below 2,500 grams and attention-deficit hyperactivity disorder in Thai children. 88(11), 1514-1518.

24. Shillingford, M. A., Lambie, G. W. \& Walter, S. M. (2007). An integrative, cognitive- behavioural,systemic approach to working with students diagnosed with attention deficit hyperactive disorder. Professional School Counseling. 11(2) 105-112.

25. Timothy E. Wilens, M. D \& Thomas J. Spencer,M.D. 2013). Understanding Attention- Deficit/Hyperactivity Disorder From Childhood to Adulthood. https://www.ncbi.nlm.nih.gov/pmc/articles/PMC3724232/

26. Steven A. Safren, P. (2021) Cognitive-Behavioral approaches to ADHD treatment in adulthood.

https://www.psychiatrist.com/wpcontent/uploads/2021/02/24240_cognitive-behavioral-approachesadhd-treatment-adulthood.pdf

27. Weiss, M., Murray, C., Wasdell, M.,Greenfield, B.,Giles, L., \& Hechtman L. (2012). A randomized controlled trial of CBT therapy for adults with ADHD with and without medication. https://bmcpsychiatry.biomedcentral.com/articles/10.1186/147 $1-244 \mathrm{X}-12-30$ 